\title{
Neighbourhood Deprivation, Individual-Level Familial and Socio-Demographic Factors and Diagnosed Childhood Obesity: A Nationwide Multilevel Study from Sweden
}

\author{
Xinjun Li ${ }^{a} \quad$ Ensieh Memarian ${ }^{a} \quad$ Jan Sundquist ${ }^{a}{ }^{b} \quad$ Bengt Zöller $^{a}$ \\ Kristina Sundquist ${ }^{\mathrm{a}, \mathrm{b}}$ \\ ${ }^{a}$ Centre for Primary Health Care Research, Lund University/Region Skåne, Malmö, \\ Sweden; ${ }^{b}$ Stanford Prevention Research Center, Stanford University School of Medicine, \\ Stanford, CA, USA
}

\section{What Is Already Known about This Subject?}

- Childhood obesity is a major health risk in childhood.

- Childhood obesity is thought to be caused by environmental and inherited factors.

- Neighbourhood environments have been shown to be an important independent risk factor for many childhood health problems.

- Management of incidentally discovered adrenal masses in FAP patients should be the same as the one for the normal population.

\section{What This Study Adds?}

- Neighbourhood deprivation exerts an independent effect on childhood obesity.

- Maternal marital status, parental low level education, advanced paternal age, family history of obesity, diabetes, chronic obstructive pulmonary disease, alcoholism, individual age, female gender and comorbidity of diabetes were associated with higher odds of childhood obesity.

- Clinicians and decision-makers should take into account the potentially negative effect of neighbourhood deprivation on childhood obesity. 


\title{
Key Words
}

Childhood obesity · Neighbourhood-level deprivation · Incidence · Socio-demographic factors $\cdot$ Multilevel modelling

\begin{abstract}
Objectives: To examine whether there is an association between neighbourhood deprivation and diagnosed childhood obesity, after accounting for family- and individual-level socio-demographic characteristics. Methods: An open cohort of all children aged 0-14 years was followed between January 1, 2000 and December 31, 2010. Childhood residential locations were geocoded and classified according to neighbourhood deprivation. Data were analysed by multilevel logistic regression, with family- and individual-level characteristics at the first level and level of neighbourhood deprivation at the second level. Results: During the study period, among a total of 948,062 children, 10,799 were diagnosed with childhood obesity. Age-adjusted cumulative incidence for diagnosed childhood obesity increased with increasing level of neighbourhood deprivation. Incidence of diagnosed childhood obesity increased with increasing neighbourhood-level deprivation across all family and individual-level socio-demographic categories. The odds ratio (OR) for diagnosed childhood obesity for those living in high-deprivation neighbourhoods versus those living in low-deprivation neighbourhoods was 2.44 (95\% confidence interval $(C I)=2.22-2.68)$. High neighbourhood deprivation remained significantly associated with higher odds of diagnosed childhood obesity after adjustment for family- and individual-level socio-demographic characteristics (OR $=1.70,95 \% \mathrm{CI}=$ 1.55-1.89). Age, middle level family income, maternal marital status, low level education, living in large cities, advanced paternal and maternal age, family history of obesity, parental history of diabetes, chronic obstructive pulmonary disease, alcoholism and personal history of diabetes were all associated with higher odds of diagnosed childhood obesity. Conclusions: Our results suggest that neighbourhood characteristics affect the odds of diagnosed childhood obesity independently of family- and individual-level socio-demographic characteristics.
\end{abstract}

(C) 2014 S. Karger GmbH, Freiburg

\section{Introduction}

Childhood obesity is a major health risk in children [1]. Childhood obesity is thought to be caused by environmental and inherited factors in about equal proportions [2, 3]. Many environmental risk factors are known, including lack of physical activity, large birth weight, nutritional factors and maternal tobacco smoking during pregnancy [4, 5]. Family history is an important risk factor, which has been shown in twins and adoptees [3]. There is also a growing body of evidence that suggests that individual-level socio-economic status (SES) is a risk factor for obesity [4-7]. Low SES may influence the risk of obesity in multiple ways. For example, exposure to harmful agents may result from residential, lifestyle or occupational factors, all of which may be related to SES [6]. These individual-level socio-demographic characteristics do not, however, fully explain the disparities by SES in childhood obesity risk that exist between different population groups [4-6]. Efforts have therefore been made to study whether the socio-economic environment is associated with the risk of childhood obesity. Neighbourhood environments have been shown to be an important independent risk factor for many childhood health problems [4, 6, 8-15]. However, no previous studies have investigated whether neighbourhood deprivation is associated with diagnosed childhood obesity after accounting for family and individual factors.

The present study had the following two aims: i) to determine whether the relationship between neighbourhood deprivation and odds of diagnosed childhood obesity remains signif- 
Li et al.: Neighbourhood Deprivation, Individual-Level Familial and Socio-Demographic Factors and Diagnosed Childhood Obesity: A Nationwide Multilevel Study from

Sweden

icant after adjusting for family- and individual-level socio-demographic factors; and ii) to examine possible cross-level interactions between individual-level socio-demographic factors and neighbourhood-level deprivation to determine whether neighbourhood-level deprivation has a differential effect on the odds of diagnosed childhood obesity across subgroups of families and individuals (effect modification).

\section{Material and Methods}

Data used in this study were retrieved from MigMed, a national database that contains information on the entire population of Sweden for a period of 40 years. The dataset we used contains nationwide information on parents and their offspring at the individual and neighbourhood level, including comprehensive demographic and socio-economic data. The information in MigMed comes from several Swedish national registers. The registers used in the present study were the Total Population Register, the Multi-Generation Register, the Hospital Discharge Register and the Outpatient Register. The Swedish nationwide population and health care registers have exceptionally high completeness and validity [16]. Individuals (children and their parents) were tracked using the personal identification numbers, which are assigned to each resident of Sweden. These identification numbers were replaced with serial numbers to provide anonymity. The follow-up period ran from January 1, 2000 until hospitalisation/out-patient treatment for obesity, death, emigration or the end of the study period on December 31, 2010.

\section{Outcome Variable: Diagnosed Childhood Obesity}

The outcome variable in this study was a hospital or out-patient diagnosis of childhood obesity (age at diagnosis 0-14 years) during the study period. Data on in-patient and out-patient diagnoses of obesity for 2000-2010 were retrieved from the Hospital Discharge Register and Out-Patient Register, which contain information on all hospital visits, including diagnoses. We searched these two registers for the International Classification of Diseases 10 (ICD-10) codes E65 and E66, denoting obesity as the main diagnosis during the study period. The serial numbers were used to ensure that each individual appeared only once in the dataset, for his or her first diagnosis of obesity during the study period.

\section{Neighbourhood-Level Deprivation}

The home addresses of all Swedish individuals have been geocoded to small geographic units with boundaries defined by homogeneous types of buildings. These neighbourhood areas, called small area market statistics or SAMS, each contain an average of 1,000 residents and were created by the Swedish Government-owned statistics bureau Statistics Sweden. SAMS were used as proxies for neighbourhoods, as they were in previous research $[17,18]$. Neighbourhood of residence is determined annually using the Swedish mapping, cadastral and land registration authority.

A summary index was calculated to characterise neighbourhood-level deprivation. The neighbourhood index was based on information about female and male residents aged 20-64 years because this age group represents those who are among the most socio-economically active in the population (i.e. a population group that has a stronger impact on the socio-economic structure in the neighbourhood than children, younger women and men, and retirees do). The neighbourhood index was based on four items: low education level ( $<10$ years of formal education), low income (income from all sources, including interest and dividends, that is $<50 \%$ of the median individual income), unemployment (excluding full-time students, those completing military service and early retirees), and receipt of social welfare. The index of the year 2000 was used to categorise neighbourhood deprivation as low (more than 1 SD below the mean), moderate (within 1 SD of the mean), and high (more than 1 SD above the mean) [19].

Individual-Level Socio-Demographic Variables

Sex of child: male or female.

Age ranged from 0 to 14 years and was divided into three categories: 0-4, 5-9 and 10-14 years.

Marital status was defined according to maternal marital status, categorized as i) married/cohabitating or ii) never married, widowed or divorced.

Family income was calculated as annual family income divided by the number of people in the family. The family income measure took into consideration the ages of the family members and used a weighted 
Li et al.: Neighbourhood Deprivation, Individual-Level Familial and Socio-Demographic Factors and Diagnosed Childhood Obesity: A Nationwide Multilevel Study from Sweden

system whereby small children were given lower weights than adolescents and adults. The sum of all family members' incomes was multiplied by the individual's consumption weight divided by the family members' total consumption weight. The final variable was calculated as empirical quartiles from the distribution.

Maternal and paternal education levels were categorised as completion of compulsory school or less ( $\leq 9$ years), practical high school or some theoretical high school (10-11 years) and completion of theoretical high school and/or college ( $\geq 12$ years).

Maternal and paternal country of birth was categorised as Sweden, Western country (Western Europe, USA, Canada, Oceania) and other.

Maternal urban/rural status: this variable was included because access to preventive antenatal care may vary according to urban/rural status. Mothers were classified as living in a large city, a middle-sized town or a small town/rural area. Large cities were those with a population of $\geq 200,000$ (Stockholm, Gothenburg and Malmö); middle-sized towns were towns with a population of $\geq 90,000$ but $<200,000$; small towns were towns with a population of $\geq 27,000$ and $<90,000$; and rural areas were areas with populations smaller than those of small towns. This classification yielded three equally sized groups.

Mobility: children were classified as having 'not moved' or having 'moved' to another neighbourhood with the same or a different level of deprivation within 5 years.

Maternal age at childbirth was classified as $<20,20-24,25-29,30-34,35-39,40-44$ and $\geq 45$ years) and paternal age at childbirth was classified as <20, 20-24, 25-29, 30-34, 35-39, 40-44, 45-49 and $\geq 50$ years.

Maternal, paternal and individual hospitalisations were defined as the first diagnosis from the Swedish Hospital Register during the follow-up period of i) diabetes (ICD-10 E10-E14), ii) chronic obstructive pulmonary disease (COPD) (ICD-10 J40-J47) and iii) alcohol-related liver disease (ICD-10 F10 and K70).

Because obesity is known to cluster in families, children were classified according to whether or not they had a family history (parents or siblings) of hospitalization of obesity.

Statistical Analysis

The cumulative rate of obesity was calculated for the total study population and for each subgroup after assessment of neighbourhood of residence for children. Multilevel (hierarchical) logistic regression models were used to estimate odds ratios (ORs) and 95\% confidence intervals (95\% CIs). The analyses were performed using MLwiN version 2.27 (University of Bristol, Bristol, UK). First, a null model was calculated to determine the variance among neighbourhoods. Then, to determine the crude odds of diagnosed childhood obesity by level of neighbourhood deprivation, a neighbourhood model that included only neighbourhoodlevel deprivation was calculated (model 1). Next, a full model that included neighbourhood-level deprivation, sex, age and the family- and individual-level socio-demographic variables, added simultaneously to the model, was calculated (aim 1). Finally, a full model tested for cross-level interactions between the family-and individual-level socio-demographic variables and neighbourhood-level deprivation to determine whether the effects of neighbourhood-level deprivation on diagnosed childhood obesity differed across the sociodemographic variables (aim 2).

Random effects: the between-neighbourhood variance was estimated both with and without a random intercept. It was regarded to be significant if it was more than 1.96 times the size of the standard error, which is in accordance with the precedent set in previous studies [20-22].

Ethical Considerations

This study was approved by the Ethics Committee at Lund University.

\section{Results}

In the total study population $(948,062$ children), $20 \%, 62 \%$, and $18 \%$ of children aged 0-14 years lived in low-, moderate- and high-deprivation neighbourhoods, respectively. During the follow-up period (January 1, 2000 to December 31, 2010), 10,799 children were diagnosed with obesity (table 1). Cumulatively diagnosed childhood obesity rates increased from 0.6 per 100 in neighbourhoods with low deprivation to 1.2 per 100 in neighbourhoods 
Li et al.: Neighbourhood Deprivation, Individual-Level Familial and Socio-Demographic Factors and Diagnosed Childhood Obesity: A Nationwide Multilevel Study from Sweden

Table 1. Distribution of population, number of diagnosed childhood obesity events, and age-standardized cumulative rates (per 100) by neighbourhood-level deprivation

\begin{tabular}{|c|c|c|c|c|c|c|c|}
\hline & \multicolumn{2}{|c|}{ Population } & \multicolumn{2}{|c|}{ Obesity events } & \multicolumn{3}{|c|}{ Neighbourhood deprivation } \\
\hline & no. & $\%$ & no. & $\%$ & low & moderate & high \\
\hline Total population (\%) & 948,062 & & & & $\begin{array}{l}187,942 \\
(20 \%)\end{array}$ & $\begin{array}{l}590,306 \\
(62 \%)\end{array}$ & $\begin{array}{l}169,814 \\
(18 \%)\end{array}$ \\
\hline Total obesity events & & & 10,799 & & 0.6 & 1.2 & 1.6 \\
\hline \multicolumn{8}{|l|}{ Gender } \\
\hline Boys & 486,690 & 51.3 & 5,565 & 51.5 & 0.6 & 1.2 & 1.6 \\
\hline Girls & 461,372 & 48.7 & 5,234 & 48.5 & 0.7 & 1.1 & 1.6 \\
\hline \multicolumn{8}{|l|}{ Age, years } \\
\hline $0-4$ & 261,589 & 27.6 & 3,102 & 28.7 & 0.6 & 1.2 & 1.7 \\
\hline $5-9$ & 340,657 & 35.9 & 4,437 & 41.1 & 0.7 & 1.3 & 1.9 \\
\hline $10-14$ & 345,816 & 36.5 & 3,260 & 30.2 & 0.6 & 1.0 & 1.3 \\
\hline \multicolumn{8}{|l|}{ Family income } \\
\hline Low income & 237,681 & 25.1 & 3,128 & 29.0 & 0.8 & 1.3 & 1.5 \\
\hline Middle-low income & 237,772 & 25.1 & 3,065 & 28.4 & 0.7 & 1.3 & 1.8 \\
\hline Middle-high income & 236,484 & 24.9 & 2,605 & 24.1 & 0.7 & 1.1 & 1.7 \\
\hline High income & 236,125 & 24.9 & 2,001 & 18.5 & 0.5 & 1.0 & 1.5 \\
\hline \multicolumn{8}{|l|}{ Marital status } \\
\hline Married/cohabiting & 553,494 & 58.4 & 5,566 & 51.5 & 0.6 & 1.1 & 1.4 \\
\hline Never married, widowed, or divorced & 394,568 & 41.6 & 5,233 & 48.5 & 0.7 & 1.3 & 1.9 \\
\hline \multicolumn{8}{|l|}{ Maternal educational attainment } \\
\hline$\leq 9$ years & 298,224 & 31.5 & 4,476 & 41.4 & 1.0 & 1.5 & 1.7 \\
\hline 10-11 years & 360,568 & 38.0 & 4,434 & 41.1 & 0.7 & 1.3 & 1.7 \\
\hline$\geq 12$ years & 289,270 & 30.5 & 1,889 & 17.5 & 0.4 & 0.7 & 1.0 \\
\hline \multicolumn{8}{|l|}{ Paternal educational attainment } \\
\hline$\leq 9$ years & 314,863 & 33.2 & 4,661 & 43.2 & 1.0 & 1.5 & 1.7 \\
\hline 10-11 years & 357,220 & 37.7 & 4,354 & 40.3 & 0.8 & 1.2 & 1.6 \\
\hline$\geq 12$ years & 275,979 & 29.1 & 1,784 & 16.5 & 0.4 & 0.7 & 1.2 \\
\hline \multicolumn{8}{|l|}{ Maternal immigrant status } \\
\hline Sweden & 818,028 & 86.3 & 8,955 & 82.9 & 0.6 & 1.1 & 1.7 \\
\hline Western countries & 59,398 & 6.3 & 755 & 7.0 & 0.7 & 1.4 & 1.4 \\
\hline Other countries & 70,636 & 7.5 & 1,089 & 10.1 & 1.0 & 1.5 & 1.6 \\
\hline \multicolumn{8}{|l|}{ Paternal immigrant status } \\
\hline Sweden & 817,772 & 86.3 & 8,907 & 82.5 & 0.6 & 1.1 & 1.7 \\
\hline Western countries & 62,948 & 6.6 & 788 & 7.3 & 0.7 & 1.3 & 1.3 \\
\hline Other countries & 67,342 & 7.1 & 1,104 & 10.2 & 1.2 & 1.7 & 1.6 \\
\hline \multicolumn{8}{|l|}{ Urban/rural status } \\
\hline Large cities & 280,040 & 29.5 & 3,541 & 32.8 & 0.6 & 1.3 & 2.1 \\
\hline Middle-sized towns & 382,270 & 40.3 & 4,305 & 39.9 & 0.6 & 1.1 & 1.7 \\
\hline Small towns/rural areas & 285,752 & 30.1 & 2,953 & 27.3 & 0.7 & 1.1 & 1.2 \\
\hline \multicolumn{8}{|l|}{ Mobility } \\
\hline Not moved & 578,542 & 61.0 & 6,155 & 57.0 & 0.6 & 1.1 & 1.6 \\
\hline Moved & 369,520 & 39.0 & 4,644 & 43.0 & 0.7 & 1.3 & 1.6 \\
\hline
\end{tabular}


Li et al.: Neighbourhood Deprivation, Individual-Level Familial and Socio-Demographic Factors and Diagnosed Childhood Obesity: A Nationwide Multilevel Study from Sweden

Table 1. Continued

\begin{tabular}{|c|c|c|c|c|c|c|c|}
\hline & \multicolumn{2}{|c|}{ Population } & \multicolumn{2}{|c|}{ Obesity events } & \multicolumn{3}{|c|}{ Neighbourhood deprivation } \\
\hline & no. & $\%$ & no. & $\%$ & low & moderate & high \\
\hline \multicolumn{8}{|l|}{ Maternal age at child birth, years } \\
\hline$<30$ & 545,120 & 57.5 & 6,217 & 57.6 & 0.7 & 1.1 & 1.6 \\
\hline $30-39$ & 380,422 & 40.1 & 4262 & 39.5 & 0.6 & 1.2 & 1.6 \\
\hline$\geq 40$ & 22,520 & 2.4 & 320 & 3.0 & 0.8 & 1.4 & 2.1 \\
\hline \multicolumn{8}{|l|}{ Paternal age at child birth, years } \\
\hline$<30$ & 365,427 & 38.5 & 4,229 & 39.2 & 0.6 & 1.2 & 1.6 \\
\hline $30-39$ & 485,142 & 51.2 & 5,175 & 47.9 & 0.6 & 1.1 & 1.6 \\
\hline$\geq 40$ & 97,493 & 10.3 & 1,395 & 12.9 & 0.9 & 1.4 & 2.0 \\
\hline \multicolumn{8}{|l|}{ Maternal hospitalization of diabetes } \\
\hline No & 939,772 & 99.1 & 10,493 & 97.2 & 0.6 & 1.1 & 1.6 \\
\hline Yes & 8,290 & 0.9 & 306 & 2.8 & 2.3 & 3.6 & 4.7 \\
\hline \multicolumn{8}{|l|}{$\begin{array}{l}\text { Maternal hospitalization of chronic lower } \\
\text { respiratory disease }\end{array}$} \\
\hline No & 938,197 & 99.0 & 10,556 & 97.7 & 0.6 & 1.2 & 1.6 \\
\hline Yes & 9,865 & 1.0 & 243 & 2.3 & 1.7 & 2.4 & 3.5 \\
\hline \multicolumn{8}{|l|}{$\begin{array}{l}\text { Maternal hospitalization of alcoholism and } \\
\text { related liver disease }\end{array}$} \\
\hline No & 938,744 & 99.0 & 10,631 & 98.4 & 0.6 & 1.2 & 1.6 \\
\hline Yes & 9,318 & 1.0 & 168 & 1.6 & 1.7 & 1.5 & 2.8 \\
\hline \multicolumn{8}{|l|}{ Paternal hospitalization of diabetes } \\
\hline No & 932,296 & 98.3 & 10,411 & 96.4 & 0.6 & 1.1 & 1.6 \\
\hline Yes & 15,766 & 1.7 & 388 & 3.6 & 1.5 & 2.4 & 3.2 \\
\hline $\begin{array}{l}\text { Paternal hospitalization of chronic lower } \\
\text { respiratory disease }\end{array}$ & & 0.0 & & 0.0 & & & \\
\hline No & 941,246 & 99.3 & 10,642 & 98.5 & 0.6 & 1.2 & 1.6 \\
\hline Yes & 6,816 & 0.7 & 157 & 1.5 & 1.9 & 2.2 & 2.9 \\
\hline \multicolumn{8}{|l|}{$\begin{array}{l}\text { Paternal hospitalization of alcoholism and } \\
\text { related liver disease }\end{array}$} \\
\hline No & 927,070 & 97.8 & 10,400 & 96.3 & 0.6 & 1.2 & 1.6 \\
\hline Yes & 20,992 & 2.2 & 399 & 3.7 & 1.3 & 1.8 & 2.3 \\
\hline \multicolumn{8}{|l|}{ Hospitalization of diabetes } \\
\hline No & 941,835 & 99.3 & 10,614 & 98.3 & 0.6 & 1.2 & 1.6 \\
\hline Yes & 6,227 & 0.7 & 185 & 1.7 & 2.1 & 3.0 & 3.6 \\
\hline \multicolumn{8}{|l|}{ Family history of obesity } \\
\hline No & 911,546 & 96.1 & 8,749 & 81.0 & 0.5 & 1.0 & 1.3 \\
\hline Yes & 36,516 & 3.9 & 2,050 & 19.0 & 4.2 & 5.6 & 6.4 \\
\hline
\end{tabular}

with moderate deprivation and 1.6 per 100 in neighbourhoods with high deprivation. A similar pattern of higher rates with increasing neighbourhood deprivation was observed across all family- and individual-level socio-demographic categories.

The OR for diagnosed childhood obesity for children living in high- versus low-deprivation neighbourhoods in the crude neighbourhood-level model was 2.44 (95\% CI $=2.22$ 2.68) (table 2). High neighbourhood-level deprivation remained significantly associated with the odds of diagnosed childhood obesity after adjustment for age, gender, and the family-and individual-level socio-demographic variables $(\mathrm{OR}=1.70,95 \% \mathrm{CI}=1.55-1.87 ; \mathrm{p}<0.001)$, compared to low-deprivation neighbourhoods. The odds of diagnosed childhood obesity was highest in children in the following subgroups among the included variables: advanced 
Li et al.: Neighbourhood Deprivation, Individual-Level Familial and Socio-Demographic Factors and Diagnosed Childhood Obesity: A Nationwide Multilevel Study from

Sweden

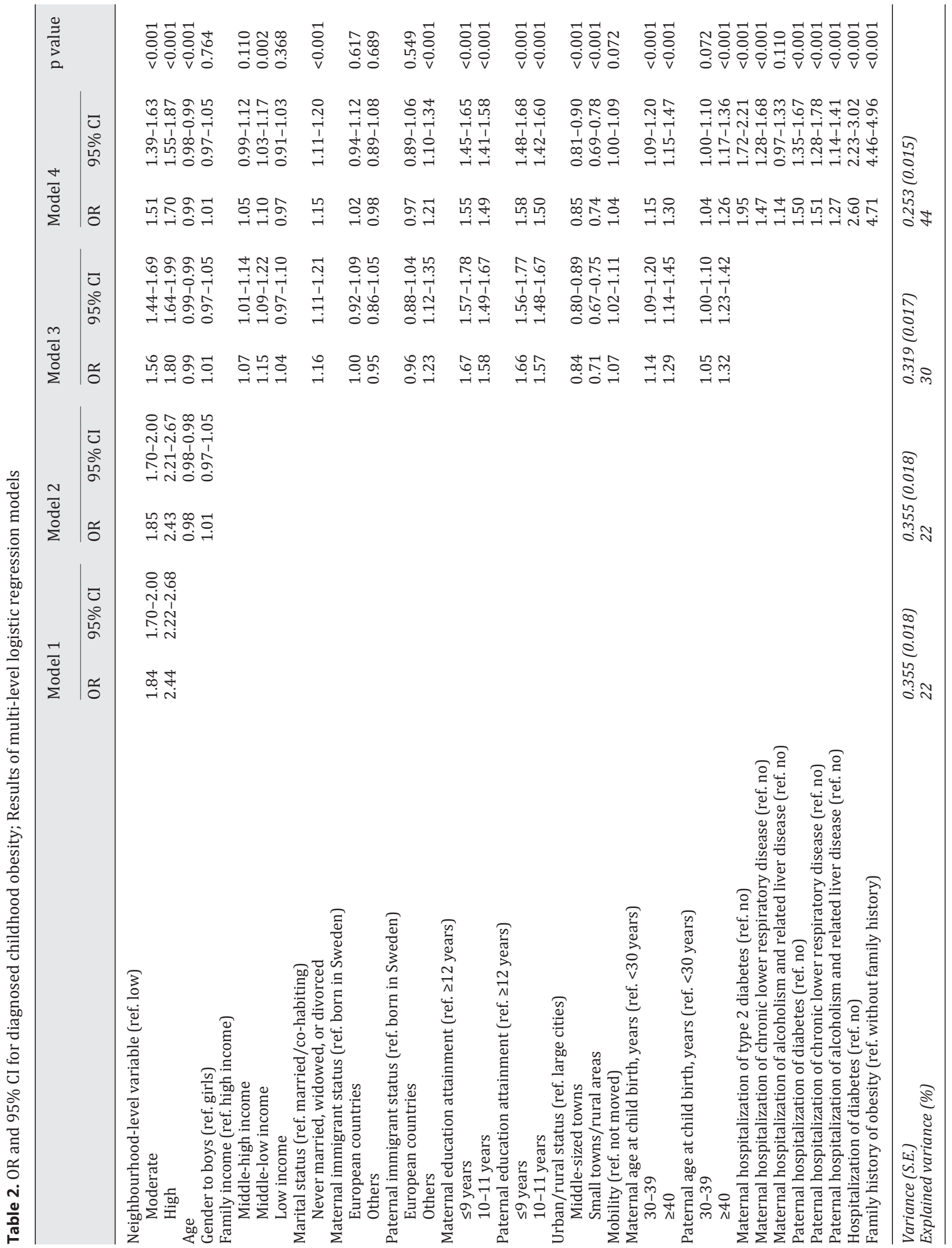


Li et al.: Neighbourhood Deprivation, Individual-Level Familial and Socio-Demographic Factors and Diagnosed Childhood Obesity: A Nationwide Multilevel Study from Sweden

parental age at birth, living in large cities, hospitalisation for diabetes, parents who were never married, widowed or divorced, parental low educational level, family moved within 5 years, advanced paternal age at childbirth, a family history of obesity, mothers hospitalised for type 2 diabetes or chronic lower respiratory disease, fathers with non-European country immigration background, fathers hospitalised for diabetes, chronic lower respiratory disease or alcohol-related liver disease.

A test for cross-level interactions between the individual-level socio-demographic variables and neighbourhood-level deprivation in the context of odds of diagnosed childhood obesity showed no meaningful cross-level interactions or effect modification.

The between-neighbourhood variance (i.e. the random intercept) was more than 1.96 times the size of the standard error in all models, indicating that there were significant differences in diagnosed childhood obesity between neighbourhoods after accounting for neighbourhood deprivation and the individual-level variables. Neighbourhood deprivation explained $22 \%$ of the between-neighbourhood variance in the null model (table 2). After inclusion of the family- and individual-level variables, the explained variance was $44 \%$.

\section{Discussion}

We found that living in a deprived neighbourhood increased the odds of diagnosed childhood obesity by $70 \%$. It is noteworthy that we found this effect in a country with a comparatively strong system of universal health care and social welfare. Our finding that neighbourhood deprivation exerts an independent effect on odds of diagnosed childhood obesity is consistent with the findings of a small but growing number of studies that have provided evidence of an association between neighbourhood-level socio-economic factors and diagnosed childhood obesity [9, 10, 12, 14, 15]. Maternal marital status, parental education, paternal age, family history of obesity, co-morbidities, age and living in large cities were associated with higher odds of diagnosed childhood obesity.

Family and individual environments such as parental educational level have been reported to be associated with diagnosed childhood obesity, due to a potential influence on children's food intake and physical activity [7, 23]. Furthermore, parental smoking and alcohol consumption are associated with higher levels of BMI [24]. However, the causal pathways linking neighbourhood socio-economic deprivation and poor health in childhood are not completely understood $[4,6,8-12,14]$. One possible mediator could be psychological stress due to isolation/alienation, littered and unsafe environments, vandalism, and violent crime in deprived neighbourhoods [20,25]. It is possible that the lack of safe environments reduces residents' ability to exercise, thereby aggravating an unhealthy lifestyle. Additionally, socio-cultural norms regarding diet, smoking and physical activity could vary between neighbourhoods and affect the health of the residents and the risk of disease [15]. For instance, a Swedish study showed that cardiovascular disease risk factors including physical inactivity, obesity and smoking were more common among individuals living in deprived neighbourhoods than among those living in affluent neighbourhoods [26].

Living in deprived neighbourhoods can cause isolation from health-promoting milieus (e.g. safe places to exercise, safe side walks, bike paths, safe parks and decent housing) and services. In comparisons of wealthy nations, associations between neighbourhood characteristics and different health outcomes were inconsistent [27]. This implies that neighbourhood determinants of health are complex. Such determinants may include access to health care, education, and social services. Access to these services is uneven in the USA, where the effects of income inequalities on health are more pronounced [28]. For example, low community income is associated with higher risk of childhood obesity [12]. However, in the present 
Li et al.: Neighbourhood Deprivation, Individual-Level Familial and Socio-Demographic Factors and Diagnosed Childhood Obesity: A Nationwide Multilevel Study from Sweden

study, no large associations with family income were observed. Children with parents who were never married, widowed or divorced, with parents with lower level of education, living in large cities, with family history of obesity, with advanced paternal age, with parental co-morbidities and with a history of diabetes had higher odds of obesity. It has been reported previously that neighbourhood socio-economic change (families who moved into different level of neighbourhoods) is associated with the risk of childhood obesity [13].

Level of neighbourhood deprivation may influence risk of childhood obesity through other general mechanisms, including unfavourable health-related behaviours of women during pregnancy [5], neighbourhood social disintegration (i.e. criminality, high mobility or unemployment) [20], low social capital $[18,19,29]$, and neighbourhood stress mediated by factors that can influence immunological and/or hormonal stress reactions [30-32]. Consistent with this hypothesis are the results of a US study, which found that neighbourhood socio-economic disparities were associated with childhood and adolescent obesity [9].

The present study has several limitations. These include the possibility that some selective factors operate in the process of hospitalisation to favour certain children being hospitalised. Affordability of health care is not a selective factor in Sweden, nor is the likelihood of seeking medical advice important because of equal access to primary and hospital care [33]. It is, however, possible that residual confounding exists because socio-economic status cannot be fully measured by family income and education level. The Swedish Hospital Discharge Register contains no information about diagnostic procedures, which is a limitation, but any bias this may have caused would most likely be non-differential. However, with respect to childhood obesity, the overall diagnostic validity of the Hospital Discharge Register is close to $90 \%$ [34, 35].

The limitations of the study are countered by its strengths, which include: i) the ability to analyse data on a large national cohort of children aged 0-14 years; ii) the prospective design; iii) the completeness of the data (for example, only $1 \%$ of the data on maternal education level and family income were missing); iv) the use of small, well-defined neighbourhoods with an average of 1,000 residents; and $v$ ) the ability to adjust for a set of family- and individual-level socio-demographic factors (age, sex, family income, maternal marital status, parental country of birth, parental education level, urban/rural status, mobility, parental age, maternal and paternal hospitalisation, and family history of obesity). Accounting for family SES is particularly important, as it is a major confounder that can affect an individual's choice of neighbourhood. Another strength is the possibility to generalise our results to other populations (external validity), particularly to populations in industrialised societies.

\section{Conclusions}

This prospective nationwide study showed that, after accounting for family- and individual-level socio-demographic factors, neighbourhood deprivation was independently associated with increased odds of diagnosed childhood obesity. This finding represents valuable knowledge for health care professionals who work in socially deprived neighbourhoods.

\section{Acknowledgement}

The authors wish to thank Science Editor Stephen Gilliver for his useful comments on the text. This work was supported by ALF funding from Region Skåne awarded to Jan Sundquist and Kristina Sundquist, the EU FP7/2007-2013 grant 260715, FAS awarded to Jan Sundquist, and grants from the Swedish Research Council (awarded to Kristina Sundquist and Jan Sundquist). The registers used in the present study are maintained by Statistics Sweden and the National Board of Health and Welfare. 


\begin{tabular}{l|l}
\hline Obes Facts 2014;7:253-263 \\
\hline DOI: $10.1159 / 000365955$ & $\begin{array}{l}\text { ( ) 2014 S. Karger GmbH, Freiburg } \\
\text { www.karger.com/ofa }\end{array}$ \\
\hline
\end{tabular}

\section{Disclosure Statement}

Li et al.: Neighbourhood Deprivation, Individual-Level Familial and Socio-Demographic Factors and Diagnosed Childhood Obesity: A Nationwide Multilevel Study from Sweden

There are no competing interests.

\section{References}

1 Karnik S, Kanekar A: Childhood obesity: a global public health crisis. Int J Prev Med 2012;3:1-7.

$\rightarrow 2$ Haworth CM, Plomin R, Carnell S, Wardle J: Childhood obesity: genetic and environmental overlap with normal-range BMI. Obesity (Silver Spring) 2008;16:1585-1590.

3 Silventoinen K, Rokholm B, Kaprio J, Sorensen TI: The genetic and environmental influences on childhood obesity: a systematic review of twin and adoption studies. Int J Obes (Lond) 2010;34:29-40.

4 Bammann K, Gwozdz W, Lanfer A, Barba G, De Henauw S, Eiben G, Fernandez-Alvira JM, Kovacs E, Lissner L, Moreno LA, Tornaritis M, Veidebaum T, Pigeot I: Socioeconomic factors and childhood overweight in Europe: results from the multi-centre IDEFICS study. Pediatr Obes 2013;8:1-12.

5 Weng SF, Redsell SA, Swift JA, Yang M, Glazebrook CP: Systematic review and meta-analyses of risk factors for childhood overweight identifiable during infancy. Arch Dis Child 2012;97:1019-1026.

-6 El-Sayed AM, Scarborough P, Galea S: Socioeconomic inequalities in childhood obesity in the United Kingdom: a systematic review of the literature. Obes Facts 2012;5:671-692.

-7 Fernandez-Alvira JM, Mouratidou T, Bammann K, Hebestreit A, Barba G, Sieri S, Reisch L, Eiben G, Hadjigeorgiou C, Kovacs E, Huybrechts I, Moreno LA: Parental education and frequency of food consumption in European children: the IDEFICS study. Public Health Nutr 2013;16:487-498.

-8 Hart D, Atkins R, Matsuba MK: The association of neighborhood poverty with personality change in childhood. J Pers Soc Psychol 2008;94:1048-1061.

-9 Singh GK, Kogan MD, van Dyck PC: A multilevel analysis of state and regional disparities in childhood and adolescent obesity in the United States. J Commun Health 2008;33:90-102.

$\checkmark 10$ Navalpotro L, Regidor E, Ortega P, Martinez D, Villanueva R, Astasio P: Area-based socioeconomic environment, obesity risk behaviours, area facilities and childhood overweight and obesity: socioeconomic environment and childhood overweight. Prev Med 2012;55:102-107.

-11 Kroll ME, Stiller CA, Murphy MF, Carpenter LM: Childhood leukaemia and socioeconomic status in England and Wales 1976-2005: evidence of higher incidence in relatively affluent communities persists over time. Br J Cancer 2011;105:1783-1787.

12 Shih M, Dumke K, Goran MI, Simon P: The association between community-level economic hardship and childhood obesity prevalence in Los Angeles. Pediatr Obes 2013;8:411-417.

-13 Grigsby-Toussaint DS, Lipton R, Chavez N, Handler A, Johnson TP, Kubo J: Neighborhood socioeconomic change and diabetes risk: findings from the Chicago childhood diabetes registry. Diabetes Care 2010;33: 1065-1068.

14 Saelens BE, Sallis JF, Frank LD, Couch SC, Zhou C, Colburn T, Cain KL, Champman J, Glanz K: Obesogenic neighborhood environments, child and parent obesity: the neighborhood impact on kids study. Am J Prev Med 2012; 42:e57-e64.

15 Singh GK, Siahpush M, Kogan MD: Neighborhood socioeconomic conditions, built environments, and childhood obesity. Health Affairs 2010;29:503-512.

16 Rosen M, Hakulinen T: Use of disease registers; in Ahrens W, Pigeot I (eds): Handbook of Epidemiology. Berlin, Springer, 2005, pp 232-251.

17 Cubbin C, Sundquist K, Ahlen H, Johansson SE, Winkleby MA, Sundquist J: Neighborhood deprivation and cardiovascular disease risk factors: protective and harmful effects. Scand J Public Health 2006;34:228-237.

-18 Sundquist J, Johansson SE, Yang M, Sundquist K: Low linking social capital as a predictor of coronary heart disease in Sweden: a cohort study of 2.8 million people. Soc Sci Med 2006;62:954-963.

19 Winkleby M, Sundquist K, Cubbin C: Inequities in CHD incidence and case fatality by neighborhood deprivation. Am J Prev Med 2007;32:97-106.

20 Sundquist K, Theobald H, Yang M, Li X, Johansson SE, Sundquist J: Neighborhood violent crime and unemployment increase the risk of coronary heart disease: a multilevel study in an urban setting. Soc Sci Med 2006; 62:2061-2071.

-21 Johnell K, Lindstrom M, Melander A, Sundquist J, Eriksson C, Merlo J: Anxiolytic-hypnotic drug use associated with trust, social participation, and the miniaturization of community: a multilevel analysis. Soc Sci Med 2006; 62:1205-1214.

-22 Johnell K, Lindstrom M, Sundquist J, Eriksson C, Merlo J: Individual characteristics, area social participation, and primary non-concordance with medication: a multilevel analysis. BMC Public Health 2006;6:52.

23 Fernandez-Alvira JM, De Bourdeaudhuij I, Singh AS, Vik FN, Manios Y, Kovacs E, Jan N, Brug J, Moreno LA: Clustering of energy balance-related behaviors and parental education in European children: the ENERGY-project. Int J Behav Nutr Phys Act 2013;10:5.

24 Khanolkar AR, Byberg L, Koupil I: Parental influences on cardiovascular risk factors in Swedish children aged 5-14 years. Eur J Public Health 2012;22:840-847. 
Li et al.: Neighbourhood Deprivation, Individual-Level Familial and Socio-Demographic Factors and Diagnosed Childhood Obesity: A Nationwide Multilevel Study from Sweden

25 Holden L, Scuffham P, Hilton M, Vecchio N, Whiteford H: Psychological distress is associated with a range of high-priority health conditions affecting working Australians. Aust N Z J Public Health 2010;34:304-310.

26 Sundquist J, Malmstrom M, Johansson SE: Cardiovascular risk factors and the neighbourhood environment: a multilevel analysis. Int J Epidemiol 1999, 28:841-845.

-27 Lynch J, Smith GD, Hillemeier M, Shaw M, Raghunathan T, Kaplan G: Income inequality, the psychosocial environment, and health: comparisons of wealthy nations. Lancet 2001;358:194-200.

28 Lochner K, Pamuk E, Makuc D, Kennedy BP, Kawachi I: State-level income inequality and individual mortality risk: a prospective, multilevel study. Am J Public Health 2001;91:385-391.

-29 Lofors J, Sundquist K: Low-linking social capital as a predictor of mental disorders: a cohort study of 4.5 million Swedes. Soc Sci Med 2007;64:21-34.

-30 Daniel M, Moore S, Kestens Y: Framing the biosocial pathways underlying associations between place and cardiometabolic disease. Health Place 2008;14:117-132.

-31 Brosschot JF, Benschop RJ, Godaert GL, Olff M, De Smet M, Heijnen CJ, Ballieux RE: Influence of life stress on immunological reactivity to mild psychological stress. Psychosom Med 1994;56:216-224.

32 McEwen BS, Biron CA, Brunson KW, Bulloch K, Chambers WH, Dhabhar FS, Goldfarb RH, Kitson RP, Miller AH, Spencer RL, Weiss JM: The role of adrenocorticoids as modulators of immune function in health and disease: neural, endocrine and immune interactions. Brain Res Brain Res Rev 1997;23:79-133.

-33 van Doorslaer E, Wagstaff A, Bleichrodt H, Calonge S, Gerdtham UG, Gerfin M, Geurts J, Gross L, Hakkinen U, Leu RE, O’Donnell O, Propper C, Puffer F, Rodriguez M, Sundberg G, Winkelhake O: Income-related inequalities in health: some international comparisons. J Health Econ 1997;16:93-112.

-34 Ludvigsson JF, Andersson E, Ekbom A, Feychting M, Kim JL, Reuterwall C, Heurgren M, Olausson PO: External review and validation of the Swedish national inpatient register. BMC Public Health 2011;11:450.

35 Centre for Epidemiology: Validity of the Diagnoses from the Swedish In-Care Register 1987 and 1995 (in Swedish). Stockholm, National Board of Health and Welfare, 2000. 